\title{
Prevalence of Frailty in End-Stage Renal Disease: A Systematic Review and Meta-analysis
}

Gotaro Kojima, MD ${ }^{1}$

${ }^{1}$ Japan Green Medical Centre, London, United Kingdom.

Corresponding Author:

Gotaro Kojima, MD

Japan Green Medical Centre

10 Throgmorton Avenue,

London, EC2N 2DL, United Kingdom

Email: gotarokojima@yahoo.co.jp

Phone: +44(0)20-7330-1750

Fax: +44(0)20-7330-1751 


\begin{abstract}
Purpose: The purpose of this study is to perform a systematic review and meta-analysis on prevalence of frailty among patients with End-stage renal disease (ESRD). ESRD is associated with malnutrition, chronic inflammation, acidemia, impaired hormonal changes, and low physical activity, all of which can directly and indirectly contribute to the development of frailty. Coexistence of ESRD and frailty has been shown to increase risks of adverse health outcomes. Given potential reversibility of frailty, it is important to examine frailty status in this high risk population.
\end{abstract}

Methods: Three databases (Embase, Medline, and CINAHL) were systematically searched for studies providing cross-sectional data of prevalence of frailty defined by Cardiovascular Health Study (CHS) criteria among ESRD patients. Meta-analysis calculated pooled prevalence of frailty according to modifications of CHS criteria.

Results: Of 837 studies identified through the systematic review, seven studies were included. Three studies used both objectively measured and self-reported CHS criteria, and two studies each used only either criteria. Pooled prevalence of frailty was $36.8 \%$ (five studies: $95 \% \mathrm{CI}=29.9-44.1 \%, \mathrm{I} 2=82.6 \%, \mathrm{p}<0.001$ ) and $67.0 \%$ (five studies: $95 \% \mathrm{CI}=58.7$ $74.7 \%, \mathrm{I} 2=82.6 \%, \mathrm{p}<0.001)$ according to the objectively measured and self-reported CHS criteria, respectively.

Conclusions: More than one third of ESRD patients were frail based on the objectively measured CHS criteria, and that prevalence of frailty almost doubled with the CHS criteria substituting self-reported physical function questionnaire score for objective measurements. Given substantial difference in prevalence of frailty depending on the modifications to CHS criteria, this information should be taken into account when evaluating frailty status among ESRD population.

Keywords: End-stage renal disease; Hemodialysis; Chronic kidney disease; Frailty; Prevalence. 


\section{INTRODUCTION}

Frailty has been described as an age-related fragile state characterized by a lack of physiological reserve with a declined ability to resist stressors,[1,2] leading to increased risks of adverse health outcomes including falls,[3] fracture,[4] hospitalization,[5] institutionalization,[6] disability,[7] dementia,[8] and poor quality of life.[9] The most frequently used definition of frailty is a frailty phenotype that Fried and colleagues originally conceptualized in 2001 among community-dwelling people aged 65 years and older from the Cardiovascular Health Study (CHS).[2] The criteria consist of five physical components: unintentional weight loss, exhaustion, weakness, slow walking speed, and low physical activity, and frailty is defined as meeting any three or more of the five components.[2] Frailty has been extensively studied in the general population and its weighted overall prevalence among community-dwelling people aged 65 or older is approximately $10 \%$ with risk factors of advanced age and female gender.[10] In contrast, there has been a relatively limited amount of research conducted among selected samples, such as institutionalized[11] and surgical patients,[12] or those with specific medical conditions such as cardiovascular disease,[13] cancers,[14] and HIV.[15] As expected, these high risk populations have been shown to have an increased prevalence of frailty.

Chronic kidney disease (CKD) is a condition associated with malnutrition, chronic inflammation, acidemia, impaired hormonal changes, and low physical activity,[16-18] all of which can directly and indirectly contribute to accelerated aging process, and possibly to the development of frailty.[19] Although CKD itself is a predictor of adverse health outcomes, coexistence of CKD and frailty has been shown to further increase risks of falls, fractures, hospitalization, and mortality.[20-22] Individuals with CKD are at a higher risk of frailty, and prevalence of frailty increases as renal function declines, with the highest prevalence among patients with end-stage renal disease (ESRD).[22-26]

In light of the fact that frailty is highly common and predicts adverse health outcomes in the CKD population, as well as a potential reversibility of frailty by appropriate interventions,[1] it is of importance to examine frailty status in the ESRD population, who are at the highest risk among CKD patients. The objectives of this systematic review and meta-analysis were to perform a systematic search of the literature regarding frailty status in ESRD patients and to synthesize pooled estimates of frailty prevalence. This review also paid attention to definitions of frailty and their modifications.

\section{METHOD}

\section{Data Source and Search Strategy}

This study was conducted based on a protocol created according to the Preferred Reporting Items for Systematic Reviews and Meta-analysis (PRISMA) guidelines.[27] One investigator (GK) searched three electronic databases (Embase, Medline, and CINAHL Plus) in June 2016 without language restriction and using the explosion function if available. The publication year was limited to between 2000 and June 2016 since Fried's original article outlining CHS criteria was published in 2001.[2] The ESRD-related search terms used, as appropriate for each database, are: Renal insufficiency (Medical Subject Heading (MeSH)) OR Kidney failure (MeSH) OR Renal insufficiency, Chronic (MeSH) OR Kidney failure, Chronic (MeSH) OR Dialysis (MeSH) OR Renal dialysis (MeSH) OR Dialysis patients (MeSH) OR Peritoneal dialysis (MeSH) OR "end stage kidney disease" OR "end stage renal disease" OR “" "ESRD” OR "ESRF” OR "ESKF” OR "ESKD” OR "dialysis" OR "hemodialysis" OR "haemodialysis" OR "peritoneal dialysis", AND the following frailty-related terms: Frail elderly (MeSH) OR Frailty syndrome (MeSH) OR “frailty”. Reference lists of relevant 
articles were also searched manually for addition studies.

\section{Study Selection}

One investigator (GK) screened the titles, abstracts, and full texts of studies identified by the systematic search of the literature. Studies were considered to be potentially eligible if their study designs were cross-sectional or prospective providing cross-sectional data on the prevalence of frailty based on the original or modified CHS criteria in patients with ESRD. The ESRD was defined for this review as stage 5 CKD or being on hemodialysis or peritoneal dialysis, and the patients with stage 5 CKD managed conservatively or supportively without dialysis treatment were not included. Studies were excluded if they included patients with stage 1-4 CKD and were a randomized clinical trial, review, editorial, comment, or conference abstract. Gray literature, such as conference abstracts, was not pursued in this review since it is often difficult or not possible in these situations to assess detailed information. The corresponding author of a potentially eligible study was contacted for additional data necessary for a meta-analysis. If the same or overlapping cohort was used by two or more studies, the one with the largest sample size was selected for this review.

\section{Data Extraction}

The following pertinent data were extracted from each eligible study by the same investigator (GK): first author, cohort/study name if any, country, sample size, mean age, age range, proportion of females, frailty criteria, modifications to the frailty criteria if any, and the numbers of those who were classified as frail, prefrail, and robust/non-frail.

\section{Statistical Analysis}

The numbers of an entire cohort and those who were classified as frail were extracted from each study and were used to calculate the pooled prevalence of frailty via a meta-analysis. A chi-square test was used to assess heterogeneity among the included studies. If the $p$ value was less than 0.05 , it was considered to have significant heterogeneity. The $\mathrm{I}^{2}$ statistic was used to assess the degree of heterogeneity, with an $\mathrm{I}^{2}$ value of $25 \%, 50 \%$, and $75 \%$ considered as low, moderate, and high degrees of the heterogeneity, respectively.[28] The pooled prevalence of frailty was calculated using a random-effects model if heterogeneity was present, and by a fixed-effects model if not, along with a $95 \%$ confidence interval $(95 \% \mathrm{CI})$. The Begg-Mazumdar's test[29] and Egger's test[30] were used to assess publication bias. Statistical analyses were conducted using StatsDirect (ver. 2.8, StatsDirect, Cheshire, UK), and the level of statistical significance was set at a $\mathrm{p}$ value of less than 0.05 .

\section{RESULTS}

\section{Selection Processes}

A flow chart of the study selection is shown in Figure 1. The systematic search of the three databases yielded 837 studies. After 260 duplicate studies were excluded, a further 553 studies were excluded through title and abstract screening. Of the 24 studies left, 17 studies were excluded during the full-text review due to using the same cohorts $(n=8)$, non-CHS criteria $(n=5)$, non-ESRD patients $(n=1)$, or being a comment $(n=1)$, a letter $(n=1)$, or news article $(n=1)$. One study included patients receiving not only hemodialysis or peritoneal dialysis, but also pre-dialysis care, and was included after data on only the hemodialysis or peritoneal dialysis patients were provided by the authors upon request.[26] Finally, seven studies were included for this review.

\section{Study Characteristics}

All seven studies used modified CHS criteria to define frailty. The data were divided, based 
on the modifications, into two study groups: (1) studies that objectively measured physical performance, such as gait speed and strength, as in Fried's original paper, and (2) studies that substituted the self-reported questionnaire score on physical function for the physical performance (36-Item Short Form Survey (SF-36) Physical Functional Scale (PFS) score $<75$ in this case). Three studies[21,31,32] used both objectively measured and self-reported criteria to measure frailty in the same cohort and were summarized in both study groups. Two studies each used only objectively measured[26,33] or self-reported[34,35] frailty criteria, respectively. Altogether, five studies were included in each study group and are summarized in Table 1. While one study was published in 2007,[35] the others were published in recent years between 2012 and 2016.[21,26,31-34] Most studies were conducted in the United States[21,31-35] and only one study was from the Netherlands.[26] The sample sizes ranged from $49[26]$ to 2,275.[35] The ESRD patients used by the included studies were on hemodialysis in five studies,[21,31-34] and on either hemodialysis or peritoneal dialysis in two studies.[26,35] The mean age was 54.4-65.2 years. All studies used mixed cohorts with men and women. Four studies were prospective[21,33-35] and three were crosssectional.[26,31,32]

\section{Prevalence of Frailty}

Objectively measured frailty

High heterogeneity was observed across the studies $\left(\mathrm{I}^{2}=82.6 \%, \mathrm{p}<0.001\right)$. A random-effects model calculated the pooled prevalence of frailty among five studies using objectively measured CHS criteria to be $36.8 \%(95 \% \mathrm{CI}=29.9-44.1 \%)$.

\section{Self-reported frailty}

Since a high degree of heterogeneity was observed in five studies that used self-reported CHS criteria $\left(\mathrm{I}^{2}=96.5 \%, \mathrm{p}<0.001\right)$, a random-effect model was used. The pooled prevalence was $67.0 \%(95 \% \mathrm{CI}=58.7-74.7 \%)$.

\section{Publication Bias Assessment}

There was no evidence of publication bias in the two study groups according to BeggMazumdar's and Egger' tests (all $\mathrm{p}>0.2$ ).

\section{DISCUSSION}

In 2005, Woods and colleagues modified CHS criteria to accommodate the available data from the Women's Health Initiative Study (WHI).[36] In the original version of CHS criteria, weakness was defined as being in the lowest $20 \%$ of handgrip strength and slow walking speed was defined as being in the lowest $20 \%$ of usual walking speed.[2] For these two components, they substituted a self-reported questionnaire, the Rand-36 Physical Function Scale (PFS). The PFS scores range from 0 to 100, with a higher score indicating better physical function, and PFS $<75$ was considered as having two points for weakness and slow walking speed; $P F S \geq 75$ was considered as having zero point. The modifications were justified by correlations of PFS with walking speed $(\mathrm{r}=0.34)$ and handgrip strength $(\mathrm{r}=0.14)$ in a subsample of WHI, and frailty defined by CHS criteria with Woods' modifications predicted disability $(\mathrm{OR}=3.15)$, hospitalization $(\mathrm{OR}=1.95$ for mean number of hospitalization per year during follow up of $\geq 0.5$ compared with no hospitalization), hip fracture (HR=1.57), and mortality $(\mathrm{HR}=1.71)$.[36]

This systematic review and meta-analysis identified seven studies, encompassing 5,254 ESRD patients, and revealed that prevalence of frailty varied substantially depending on the modifications made to CHS criteria. While the pooled prevalence of frailty was $36.8 \%$ among 
five studies using objectively measured CHS criteria, the self-reported CHS criteria, which replaced strength and gait speed with the self-reported questionnaire score, showed almost twice the pooled frailty prevalence of $67.0 \%$ compared to the other five studies.

Three studies examined the effects of these substitutions comparing the objectively measured and self-reported CHS criteria in the same ESRD cohorts and all three studies showed a higher prevalence of frailty according to self-reported CHS criteria compared with the objectively measured CHS criteria.[21,31,32] Among 188 ESRD patients, while objectively measured CHS criteria classified $23.8 \%$ and $32.6 \%$ of the patients as having slow gait speed and weakness, respectively, a strikingly high proportion of the patients $(80.3 \%, 151 / 188)$ were considered to have both of these components based on the substitutions of SF-36 $\mathrm{PFS}<75$.[32] As a result, the prevalence of frailty was substantially different in the comparisons: $23.8 \%$ by objectively measured CHS criteria vs. $78.2 \%$ by self-reported CHS criteria.[32] Similarly, another study showed a higher prevalence of frailty based on selfreported CHS criteria (52.0\%) compared with that based on objectively measured CHS criteria (31.5\%) among 762 ESRD patients on hemodialysis.[21] One study lacked the data for weight loss and used the rest of the four components for objectively measured CHS criteria and meeting two or more components out of the possible four was defined as being frail.[31] For self-reported CHS criteria, the authors gave SF-36 PFS $<75$ one point, instead of two points as in other studies, along with one point each for exhaustion and low physical activity, and meeting two or more components out of the possible three was defined as frail.[31] Presumably due to the different modification from the other studies, the prevalence of frailty was similar, at $58.8 \%$ and $62.5 \%$ based on objectively measured and self-reported CHS criteria, respectively.[31]

It is not clear why prevalence of frailty differ substantially between two sets of CHS criteria with different modifications. One possibility is that both of weakness and slow gait speed were considered to be present in only lowest $20 \%$ of the entire cohort in objectively measured CHS criteria, while there is no such restriction to the proportion of those with SF-36 PF of less than 75 points in self-reported CHS criteria, possibly leading to the higher prevalence of frailty. However, regardless of the modification of the CHS criteria, both objectively measured and self-reported CHS criteria longitudinally predicted negative health outcomes in ESRD populations.[20,21,34,37] It seems too early to conclude which version of frailty criteria is better for risk assessment of ESRD patients with currently available knowledge, and further research is warranted especially regarding how longitudinal health outcomes and effects of frailty interventions may differ among ESRD patients defined as frail by whether objectively measured or self-reported CHS criteria.

Most of the included studies consistently showed, regardless of whether objectively measured or self-reported CHS criteria are used, that frail individuals were more likely to be older and female and to have comorbidities,[21,26,31-35] which are in line with previous studies of community-dwelling elderly populations.[10] Due to the lack of grouped data by these factors in these studies, stratified meta-analysis was not possible. Various studies examined prospective risks of negative health outcomes according to frailty in patients with CKD [38,39] and specifically ESRD.[21,33-35] Among the studies included in this review, one study followed over a median of 1.7 years and found that frailty defined by both objectively measured and self-reported CHS criteria predicted mortality adjusted for age, gender, race, $\mathrm{BMI}$, and comorbidity $(\mathrm{HR}=2.20,95 \% \mathrm{CI}=1.41-3.30$ for objectively measured CHS criteria; $\mathrm{HR}=1.93,95 \% \mathrm{CI}=1.24-3.00$ for self-reported CHS criteria).[21] Interestingly, the mortality risk of those who were classified as frail by only the self-reported criteria but 
not by the objectively measured criteria did not reach statistical significance $(\mathrm{HR}=1.40$, $95 \% \mathrm{CI}=0.82-2.38$ ), while those who were classified as frail by both criteria had a higher risk of mortality $(\mathrm{HR}=2.46,95 \% \mathrm{CI}=1.51-4.01) .[21]$

There are a few studies measuring frailty using other frailty definitions among ESRD populations.[26,40-42] One of the studies included in this review also used the Frailty Index and categorized those with a Frailty Index of $\geq 0.25,0.08-0.25$, and $<0.08$ as being frail, prefrail, and robust, respectively.[26] This study showed that $39.3 \%(22 / 56)$ of participants were frail.[26] Another study from Brazil used the Edmonton Frail Scale and showed that $38.3 \%$ (23/60) were frail.[40] A Canadian study reported a frailty prevalence of $25.9 \%$ based on the Clinical Frailty Scale among 390 patients with ESRD.[41] Chao and colleagues applied six different criteria (Strawbridge questionnaire, Edmonton Frail Scale, FRAIL scale, Groningen Frail Indicator, G8 questionnaire, and Tilburg Frail Indicator) to 46 Taiwanese ESRD patients on hemodialysis to show that the frailty prevalence was highly variable, from $19.6 \%$ using the FRAIL scale up to $82.6 \%$ with the G8 questionnaire.[42]

The findings of this review need to be interpreted with caution due to the following limitations. First, only a limited number of studies were identified and included in this review, and more studies are needed for a more complete understanding of this high risk ESRD population. Second, most of the studies included in this review were conducted in the US and the findings may not be generalizable to other populations. Lastly, all processes, including the systematic literature search, screening, assessment of inclusion and exclusion criteria, and data extraction, were conducted by one investigator and it is still possible that important studies may have been missed.

This study has multiple strengths. First, methodology of the systematic review was robust and reproducible, using multiple databases with extensive search terms and with the explosion function. An author of the potentially eligible study was contacted for additional data necessary for the meta-analysis.[26] Second, this was the first to quantitatively pool the prevalence of frailty among ESRD populations. Third, the meta-analysis was conducted using two study groups according to how the CHS criteria were modified - objectively measured vs. self-reported - revealing that the self-reported CHS classified nearly twice as many ESRD patients as being frail compared with the objectively measured ones. Given frail patients with ESRD are at high risks for negative health outcomes,

It is worthwhile to identify frail patients with ESRD who may potentially benefit from interventions, such as a nutritional supplement or exercise program.[39] A randomized controlled trial showed that taking a CKD-specific high-protein oral nutritional supplement with anti-inflammatory and anti-oxidative ingredients for 16 weeks significantly improved serum albumin levels in patients on maintenance hemodialysis.[16] Intradialytic exercise training has been suggested as an effective therapy for low physical activity and sarcopenia.[43] Although this therapy still lacks the evidence necessary to be standard care for ESRD patients, it appears safe and well-tolerated, and may be beneficial especially when continued for more than six months.[18]

\section{Conclusion}

This systematic review and meta-analysis highlights that more than one third of ESRD patients were frail based on objectively measured CHS criteria, and that the prevalence of frailty almost doubled when using the self-reported CHS criteria. This information should be taken into account especially when modified CHS criteria are used in this population. 


\section{ACKNOWLEDGEMENT}

The author would like to thank those who kindly shared the data on request.[26]

\section{COMPLIANCE WITH ETHICAL STANDARDS}

Funding: None.

Conflict of Interest: None.

Ethical Approval: This article does not contain any studies with human participants or animals performed by the author.

\section{REFERENCES}

1. Clegg A, Young J, Iliffe S, Rikkert MO, Rockwood K (2013) Frailty in elderly people. Lancet 381 (9868):752-762.

2. Fried LP, Tangen CM, Walston J, Newman AB, Hirsch C, Gottdiener J, Seeman T, Tracy R, Kop WJ, Burke G, McBurnie MA (2001) Frailty in older adults: evidence for a phenotype. J Gerontol A Biol Sci Med Sci 56 (3):M146-156.

3. Kojima G (2015) Frailty as a Predictor of Future Falls Among Community-Dwelling Older People: A Systematic Review and Meta-Analysis. J Am Med Dir Assoc 16 (12):1027-1033.

4. Kojima G (2016) Frailty as a predictor of fractures among community-dwelling older people: A systematic review and meta-analysis. Bone 90:116-122.

5. Kojima G (2016) Frailty as a predictor of hospitalisation among community-dwelling older people: a systematic review and meta-analysis. J Epidemiol Community Health 70 (7):722729.

6. Kojima G (2016) Frailty as a Predictor of Nursing Home Placement Among CommunityDwelling Older Adults: A Systematic Review and Meta-analysis. J Geriatr Phys Ther.

7. Kojima G (2016) Frailty as a predictor of disabilities among community-dwelling older people: a systematic review and meta-analysis. Disabil Rehabil:1-12.

8. Kojima G, Taniguchi Y, Iliffe S, Walters K (2016) Frailty as a Predictor of Alzheimer Disease, Vascular Dementia, and All Dementia Among Community-Dwelling Older People:

A Systematic Review and Meta-Analysis. J Am Med Dir Assoc 17 (10):881-888.

9. Kojima G, Iliffe S, Jivraj S, Walters K (2016) Association between frailty and quality of life among community-dwelling older people: a systematic review and meta-analysis. J Epidemiol Community Health 70 (7):716-721.

10. Collard RM, Boter H, Schoevers RA, Oude Voshaar RC (2012) Prevalence of frailty in community-dwelling older persons: a systematic review. J Am Geriatr Soc 60 (8):1487-1492. 11. Kojima G (2015) Prevalence of Frailty in Nursing Homes: A Systematic Review and Meta-Analysis. J Am Med Dir Assoc 16 (11):940-945.

12. Partridge JS, Harari D, Dhesi JK (2012) Frailty in the older surgical patient: a review. Age Ageing 41 (2):142-147.

13. Afilalo J, Karunananthan S, Eisenberg MJ, Alexander KP, Bergman H (2009) Role of frailty in patients with cardiovascular disease. Am J Cardiol 103 (11):1616-1621.

14. Handforth C, Clegg A, Young C, Simpkins S, Seymour MT, Selby PJ, Young J (2015) The prevalence and outcomes of frailty in older cancer patients: a systematic review. Ann Oncol 26 (6):1091-1101.

15. Leng SX, Margolick JB (2015) Understanding frailty, aging, and inflammation in HIV infection. Curr HIV/AIDS Rep 12 (1):25-32.

16. Rattanasompattikul M, Molnar MZ, Lee ML, Dukkipati R, Bross R, Jing J, Kim Y, Voss AC, Benner D, Feroze U, Macdougall IC, Tayek JA, Norris KC, Kopple JD, Unruh M, Kovesdy CP, Kalantar-Zadeh K (2013) Anti-Inflammatory and Anti-Oxidative Nutrition in Hypoalbuminemic Dialysis Patients (AIONID) study: results of the pilot-feasibility, double- 
blind, randomized, placebo-controlled trial. J Cachexia Sarcopenia Muscle 4 (4):247-257. 17. Kim JC, Kalantar-Zadeh K, Kopple JD (2013) Frailty and protein-energy wasting in elderly patients with end stage kidney disease. J Am Soc Nephrol 24 (3):337-351. 18. Sheng K, Zhang P, Chen L, Cheng J, Wu C, Chen J (2014) Intradialytic exercise in hemodialysis patients: a systematic review and meta-analysis. Am J Nephrol 40 (5):478-490. 19. Brown EA, Johansson L (2010) Old age and frailty in the dialysis population. J Nephrol 23 (5):502-507.

20. McAdams-DeMarco MA, Law A, Salter ML, Boyarsky B, Gimenez L, Jaar BG, Walston JD, Segev DL (2013) Frailty as a novel predictor of mortality and hospitalization in individuals of all ages undergoing hemodialysis. J Am Geriatr Soc 61 (6):896-901.

21. Johansen KL, Dalrymple LS, Glidden D, Delgado C, Kaysen GA, Grimes B, Chertow GM (2016) Association of Performance-Based and Self-Reported Function-Based Definitions of Frailty with Mortality among Patients Receiving Hemodialysis. Clin J Am Soc Nephrol 11 (4):626-632.

22. Wilhelm-Leen ER, Hall YN, M KT, Chertow GM (2009) Frailty and chronic kidney disease: the Third National Health and Nutrition Evaluation Survey. Am J Med 122 (7):664671 e662.

23. Shlipak MG, Stehman-Breen C, Fried LF, Song X, Siscovick D, Fried LP, Psaty BM, Newman AB (2004) The presence of frailty in elderly persons with chronic renal insufficiency. Am J Kidney Dis 43 (5):861-867.

24. Roshanravan B, Khatri M, Robinson-Cohen C, Levin G, Patel KV, de Boer IH, Seliger S, Ruzinski J, Himmelfarb J, Kestenbaum B (2012) A prospective study of frailty in nephrology-referred patients with CKD. Am J Kidney Dis 60 (6):912-921.

25. Dalrymple LS, Katz R, Rifkin DE, Siscovick D, Newman AB, Fried LF, Sarnak MJ, Odden MC, Shlipak MG (2013) Kidney function and prevalent and incident frailty. Clin J Am Soc Nephrol 8 (12):2091-2099.

26. Drost D, Kalf A, Vogtlander N, van Munster BC (2016) High prevalence of frailty in endstage renal disease. Int Urol Nephrol 48 (8):1357-1362.

27. Moher D, Liberati A, Tetzlaff J, Altman DG (2009) Preferred reporting items for systematic reviews and meta-analyses: the PRISMA statement. BMJ 339:b2535.

28. Higgins JP, Thompson SG, Deeks JJ, Altman DG (2003) Measuring inconsistency in meta-analyses. BMJ 327 (7414):557-560.

29. Begg CB, Mazumdar M (1994) Operating characteristics of a rank correlation test for publication bias. Biometrics 50 (4):1088-1101.

30. Egger M, Davey Smith G, Schneider M, Minder C (1997) Bias in meta-analysis detected by a simple, graphical test. BMJ 315 (7109):629-634.

31. Delgado C, Doyle JW, Johansen KL (2013) Association of frailty with body composition among patients on hemodialysis. J Ren Nutr 23 (5):356-362.

32. Painter P, Kuskowski M (2013) A closer look at frailty in ESRD: getting the measure right. Hemodial Int 17 (1):41-49.

33. McAdams-DeMarco MA, Tan J, Salter ML, Gross A, Meoni LA, Jaar BG, Kao WH, Parekh RS, Segev DL, Sozio SM (2015) Frailty and Cognitive Function in Incident Hemodialysis Patients. Clin J Am Soc Nephrol 10 (12):2181-2189.

34. Bao Y, Dalrymple L, Chertow GM, Kaysen GA, Johansen KL (2012) Frailty, dialysis initiation, and mortality in end-stage renal disease. Arch Intern Med 172 (14):1071-1077. 35. Johansen KL, Chertow GM, Jin C, Kutner NG (2007) Significance of frailty among dialysis patients. J Am Soc Nephrol 18 (11):2960-2967.

36. Woods NF, LaCroix AZ, Gray SL, Aragaki A, Cochrane BB, Brunner RL, Masaki K, Murray A, Newman AB (2005) Frailty: emergence and consequences in women aged 65 and older in the Women's Health Initiative Observational Study. J Am Geriatr Soc 53 (8):1321- 
1330.

37. Delgado C, Shieh S, Grimes B, Chertow GM, Dalrymple LS, Kaysen GA, Kornak J, Johansen KL (2015) Association of Self-Reported Frailty with Falls and Fractures among Patients New to Dialysis. Am J Nephrol 42 (2):134-140.

38. Bohm C, Storsley L, Tangri N (2015) The assessment of frailty in older people with chronic kidney disease. Curr Opin Nephrol Hypertens 24 (6):498-504.

39. Musso CG, Jauregui JR, Macias Nunez JF (2015) Frailty phenotype and chronic kidney disease: a review of the literature. Int Urol Nephrol 47 (11):1801-1807.

40. Orlandi FdS, Gesualdo GD (2014) Assessment of the frailty level of elderly people with chronic kidney disease undergoing hemodialysis. Acta Paulista de Enfermagem 27 (1):29-34. 41. Alfaadhel TA, Soroka SD, Kiberd BA, Landry D, Moorhouse P, Tennankore KK (2015) Frailty and mortality in dialysis: evaluation of a clinical frailty scale. Clin J Am Soc Nephrol $10(5): 832-840$.

42. Chao CT, Hsu YH, Chang PY, He YT, Ueng RS, Lai CF, Chiang CK, Huang JW, Huang SJ (2015) Simple self-report FRAIL scale might be more closely associated with dialysis complications than other frailty screening instruments in rural chronic dialysis patients. Nephrology (Carlton) 20 (5):321-328.

43. Cheema BS, Smith BC, Singh MA (2005) A rationale for intradialytic exercise training as standard clinical practice in ESRD. Am J Kidney Dis 45 (5):912-916. 
Figure 1. Flow chart of systematic literature review

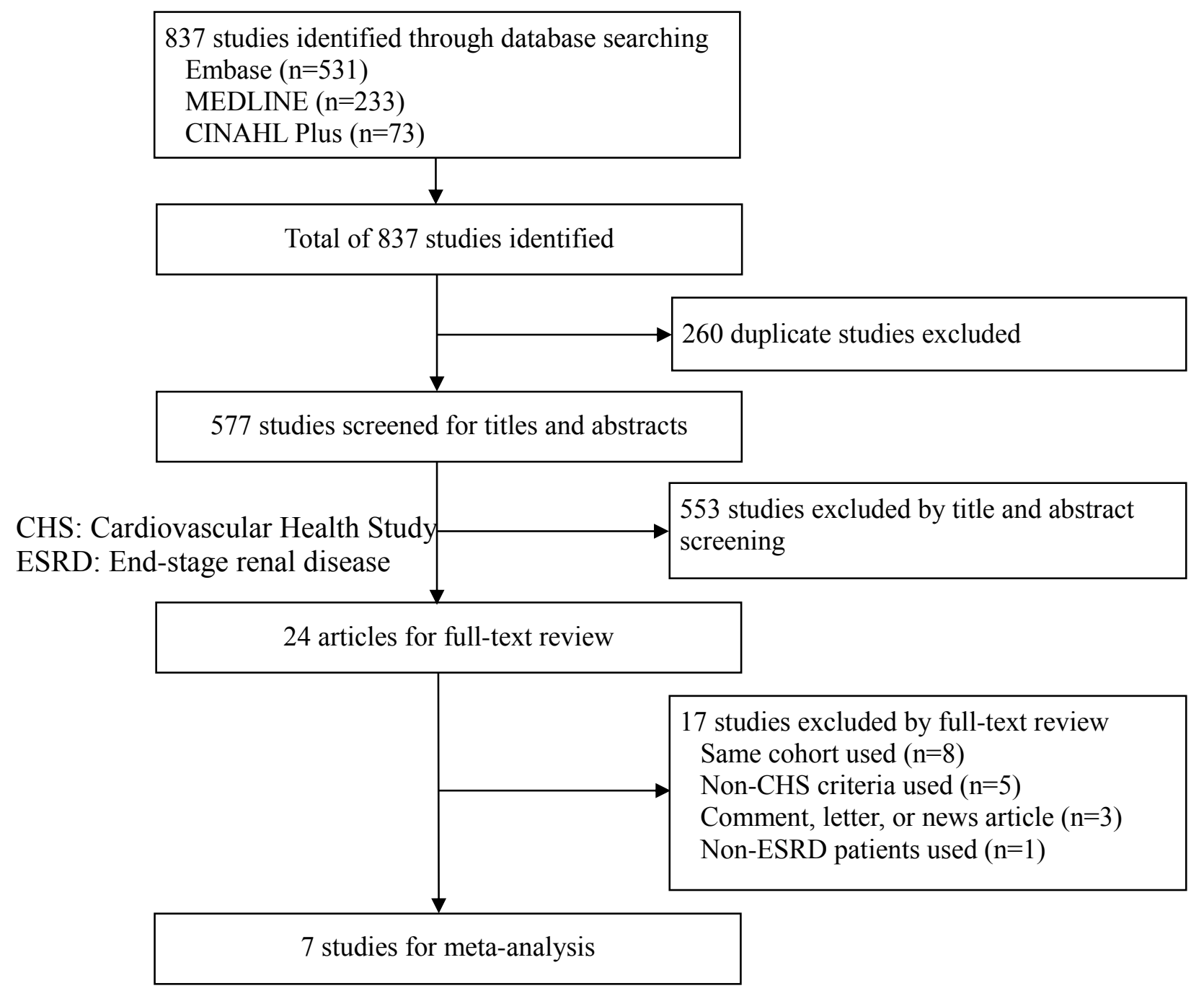


Figure 2. Forest plots of prevalence of frailty based on the Cardiovascular Health Study (CHS) criteria among patients with end-stage renal disease. A: Objectively measured frailty. B: Self-reported frailty.

A

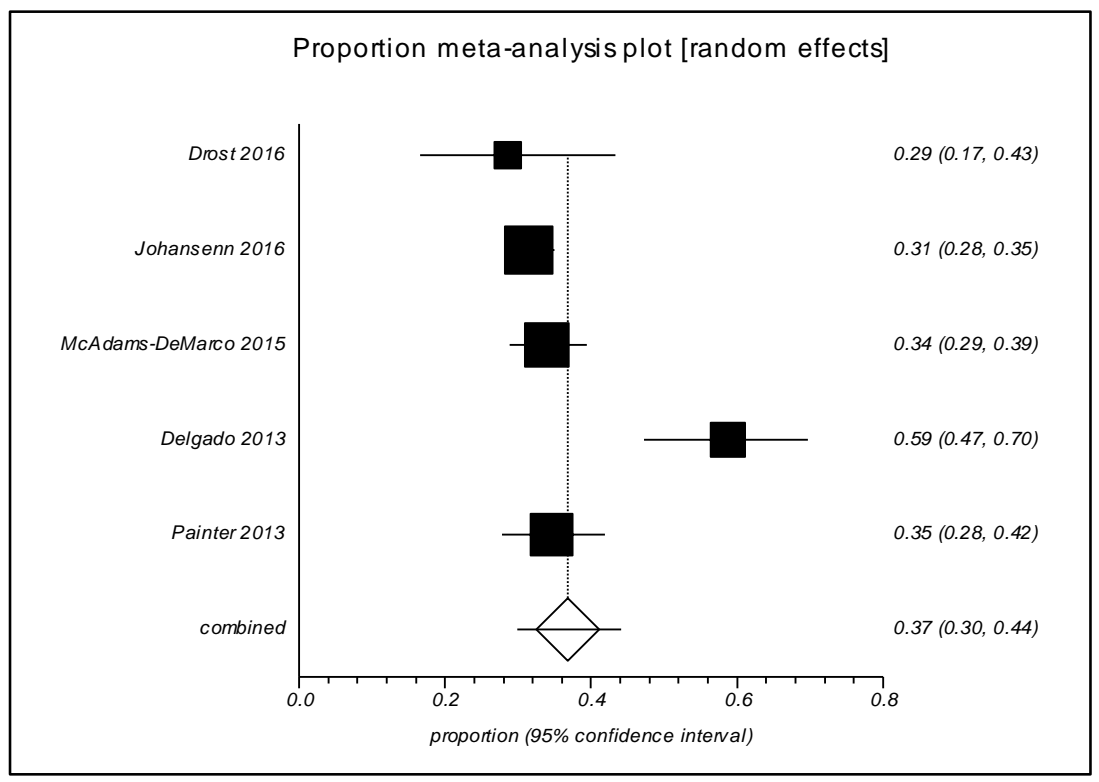

$\mathrm{B}$

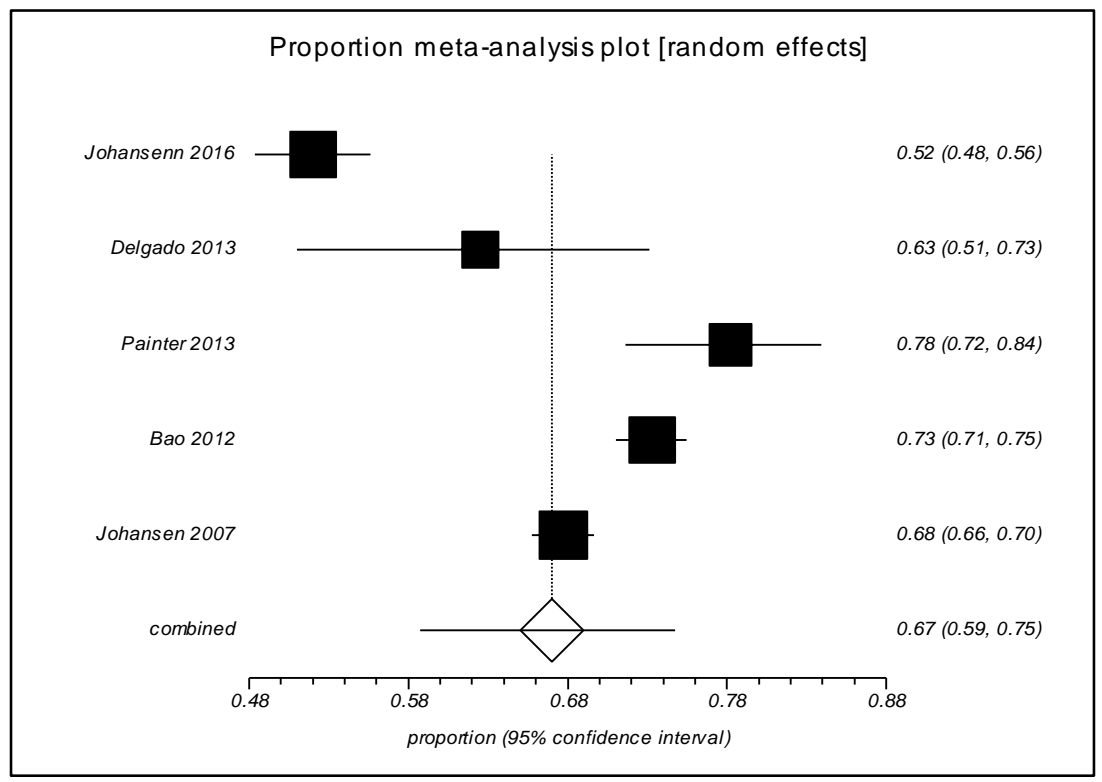


Table 1. Summary of included studies on prevalence of frailty among patients with end-stage renal disease.

\begin{tabular}{|c|c|c|c|c|c|c|c|c|}
\hline Author/Study & Country & Cohort & Age (range) & Female $(\%)$ & $\begin{array}{l}\text { modification for weakness and slow gait speed } \\
\text { components of CHS criteria }\end{array}$ & Frail & Prefrail & Robust \\
\hline \multicolumn{9}{|l|}{ mCHS (objectively measured) } \\
\hline Drost 2016[26] & Netherlands & $\begin{array}{l}\mathrm{N}=49 * \\
\text { on hemodialysis or } \\
\text { peritoneal dialysis }\end{array}$ & $65.2(27-88)$ & $43.2 \%$ & - original criteria without modification & $\begin{array}{c}28.6 \% \\
14 / 49\end{array}$ & $\begin{array}{c}22.4 \% \\
11 / 49\end{array}$ & $\begin{array}{l}49.0 \% \\
24 / 49\end{array}$ \\
\hline $\begin{array}{l}\text { Johansen 2016[21] } \\
\text { ACTIVE/ADIPOSE }\end{array}$ & USA & $\begin{array}{l}\mathrm{N}=762 \\
\text { all on hemodialysis }\end{array}$ & $\begin{array}{l}57.1 \\
(\geq 18)\end{array}$ & $40.7 \%$ & $\begin{array}{l}\text { - handgrip } \\
-15 \mathrm{ft} \text { timed walk at a usual pace }\end{array}$ & $\begin{array}{c}31.5 \% \\
240 / 762 \\
\end{array}$ & - & $\begin{array}{c}68.5 \% \\
522 / 762 \\
\end{array}$ \\
\hline McAdams-DeMarco 2015[33] & USA & $\begin{array}{l}\mathrm{N}=324 \\
\text { within } 6 \text { months of } \\
\text { hemodialysis initiation }\end{array}$ & 54.8 & $43.5 \%$ & $\begin{array}{l}\text { - handgrip } \\
\text { - } 15 \mathrm{ft} \text { timed walk }\end{array}$ & $\begin{array}{c}34.0 \% \\
110 / 324\end{array}$ & $\begin{array}{c}37.7 \% \\
122 / 324\end{array}$ & $\begin{array}{l}28.4 \% \\
92 / 324\end{array}$ \\
\hline $\begin{array}{l}\text { Delgado 2013[31] } \\
\text { NEXT }\end{array}$ & USA & $\begin{array}{l}\mathrm{N}=80 \\
\text { all on hemodialysis }\end{array}$ & $\begin{array}{l}355 " \\
(-)\end{array}$ & $37.5 \%$ & $\begin{array}{l}\text { - sit-to-stand test }>14.5 \text { seonds } \\
\text { - gait speed }<0.8 \mathrm{~m} / \mathrm{s}\end{array}$ & $\begin{array}{c}58.8 \% \\
47 / 80\end{array}$ & - & $\begin{array}{l}41.3 \% \\
33 / 80\end{array}$ \\
\hline $\begin{array}{l}\text { Painter 2013[32] } \\
\text { REXDP }\end{array}$ & USA & $\begin{array}{l}\mathrm{N}=188 \\
\text { all on hemodialysis }\end{array}$ & $\begin{array}{c}54.4 \\
(-)\end{array}$ & $56.4 \%$ & $\begin{array}{l}\text { - timed chair stand: time taken to stand up and sit } \\
\text { down five times }<16.70 \mathrm{~s} \text { (slowest quartile) } \\
-6 \mathrm{~m} \text { time walk: }<0.64 \mathrm{~m} / \mathrm{s} \text { for men }>173 \mathrm{~cm} \text { and } \\
\text { women }>159 \mathrm{~cm} \text { and }<0.75 \mathrm{~m} / \mathrm{s} \text { for men }<173 \mathrm{~cm} \\
\text { and women }<159 \mathrm{~cm} \text {. }\end{array}$ & $\begin{array}{l}34.6 \% \\
65 / 188\end{array}$ & - & $\begin{array}{c}65.4 \% \\
123 / 188\end{array}$ \\
\hline \multicolumn{9}{|l|}{ mCHS (self-reported) } \\
\hline $\begin{array}{l}\text { Johansen 2016[21] } \\
\text { ACTIVE/ADIPOSE }\end{array}$ & USA & $\begin{array}{l}\mathrm{N}=762 \\
\text { all on hemodialysis }\end{array}$ & $\begin{array}{c}57.1 \\
(\geq 18)\end{array}$ & $43.2 \%$ & $\begin{array}{l}- \text { SF-36 } \mathrm{PF}<75 \text { for both weakness and slow gait } \\
\text { ( } 2 \text { points) }\end{array}$ & $\begin{array}{c}52.0 \% \\
396 / 762\end{array}$ & - & $\begin{array}{c}48.0 \% \\
366 / 762\end{array}$ \\
\hline $\begin{array}{l}\text { Delgado 2013[31] } \\
\text { NEXT }\end{array}$ & USA & $\begin{array}{l}\mathrm{N}=80 \\
\text { all on hemodialysis }\end{array}$ & $\begin{array}{c}55 " \\
(-)\end{array}$ & $40.7 \%$ & $\begin{array}{l}- \text { SF-36 } P F<75 \text { for both weakness and slow gait } \\
\text { (1 point) }\end{array}$ & $\begin{array}{c}62.5 \% \\
50 / 80\end{array}$ & - & $\begin{array}{l}37.5 \% \\
30 / 80 \\
\end{array}$ \\
\hline $\begin{array}{l}\text { Painter 2013[32] } \\
\text { REXDP }\end{array}$ & USA & $\begin{array}{l}\mathrm{N}=188 \\
\text { all on hemodialysis }\end{array}$ & $\begin{array}{c}54.4 \\
(-)\end{array}$ & $56.4 \%$ & $\begin{array}{l}\text { - SF-36 } \mathrm{PF}<75 \text { for both weakness and slow gait } \\
\text { (2 points) }\end{array}$ & $\begin{array}{c}78.2 \% \\
147 / 188 \\
\end{array}$ & - & $\begin{array}{l}21.8 \% \\
41 / 188 \\
\end{array}$ \\
\hline $\begin{array}{l}\text { Bao 2012[34] } \\
\text { Comprehensive Dialysis Study }\end{array}$ & USA & $\begin{array}{l}\mathrm{N}=1,576 \\
\text { all on hemodialysis }\end{array}$ & $\begin{array}{c}59.6 \\
(-)\end{array}$ & $44.5 \%$ & $\begin{array}{l}- \text { SF-36 } P F<75 \text { for both weakness and slow gait } \\
\text { (1 point) }\end{array}$ & $\begin{array}{c}73.3 \% \\
1155 / 157 \\
6 \\
\end{array}$ & - & $\begin{array}{c}26.7 \% \\
\text { (nonfrail) } \\
421 / 1576 \\
\end{array}$ \\
\hline $\begin{array}{l}\text { Johansen } 2007[35] \\
\text { DMMS wave } 2\end{array}$ & USA & $\begin{array}{l}\mathrm{N}=2,275 \\
\text { on hemodialysis or } \\
\text { peritoneal dialysis }\end{array}$ & 58.2 & $46.6 \%$ & $\begin{array}{l}\text { - SF-36 PF }<75 \text { for both weakness and slow gait } \\
\text { ( } 2 \text { points) }\end{array}$ & $\begin{array}{c}67.7 \% \\
1540 / 227 \\
5 \\
\end{array}$ & - & $\begin{array}{c}32.3 \% \\
735 / 2275\end{array}$ \\
\hline
\end{tabular}

*Only those who were on hemodialysis or peritoneal dialysis were included and those who were in pre-dialysis care were excluded.

ACTIVE/ADIPOSE: A Cohort Study to Investigate the Value of Exercise in ESRD/Analyses Designed to Investigate the Paradox of Obesity and Survival in ESRD

DMMS: the Dialysis Morbidity and Mortality Study mCHS: modified Cardiovascular Health Study criteria 
NEXT: the Nandrolone and Exercise study

REXDP: the Renal Exercise Demonstration Project 